\title{
TRATAMIENTO DE LA ENFERMEDAD DE GRAVES CON ANÁLOGOS DE LA SOMATOSTATINA: CASO CLÍNICO
}

\author{
SOMATOSTATIN ANALOGUE TREATMENT IN GRAVES' \\ OPHTHALMOPATHY: A CASE REPORT
}

\author{
COLOMA-GONZÁLEZ I ${ }^{1}$, MENGUAL-VERDÚ E², DOMÍNGUEZ-ECRIBANO JR ${ }^{3}$, \\ HUESO-ABANCENS JR ${ }^{4}$
}

\begin{abstract}
RESUMEN
Caso clínico: Se presenta la evolución de un paciente con oftalmopatía de Graves (OG) tratado con análogos de la somatostatina, así como las indicaciones, pauta y resultados obtenidos.

Discusión: Son pocas las opciones terapéuticas efectivas para el manejo de la oftalmopatía asociada a disfunción tiroidea de origen autoinmune. Los análogos de la somatostatina inhiben la proliferación y activación de los linfocitos, y se acumulan en el tejido orbitario durante la fase activa de la enfermedad oftálmica. Así, nos permitieron en el caso presentado llegar a la fase inactiva de la enfermedad sin secuelas importantes.
\end{abstract}

Palabras clave: Análogos de la somatostatina, lanreótido, SOM230, enfermedad de Graves, octreoscan.

\begin{abstract}
Case report: The effect of a somatostatin analogue in a patient with Graves' ophthalmopathy is presented, including data on the dose requirements and the results of therapy.

Discussion: There are few effective options for the management of Graves' ophthalmopathy, a cellmediated immune co-morbidity of thyroid disease. Somatostatin analogues inhibit lymphocyte proliferation and activation, and accumulate in the orbital tissue during the active ophthalmopathy. Because of this, such therapy is able to inactivate the ophthalmopathy without complications occurring (Arch Soc Esp Oftalmol 2007; 82: 51-54).
\end{abstract}

Key words: Somatostatin analogues, lanreotide, SOM230, Graves' ophthalmopathy, octreoscan.

Recibido: 16/3/06. Aceptado: 20/12/06.

Hospital Universitario San Juan de Alicante. Alicante. España.

1 Licenciado en Medicina.

2 Doctor en Medicina. Jefe de Sección.

3 Doctor en Medicina. Departamento de Endocrinología.

4 Doctor en Medicina. Jefe de Servicio.

Comunicación presentada en el LXXXI Congreso de la S.E.O. (Zaragoza 2005).

Correspondencia:

Itziar Coloma González

Hospital Universitario San Juan de Alicante

Ctra. N-332 Valencia-Alicante, s/n

03550 San Juan (Alicante)

España

E-mail: icg_ct@yahoo.es 


\section{INTRODUCCIÓN}

La oftalmopatía de Graves (OG) es un proceso inflamatorio autoinmune asociado a disfunción tiroidea, aunque existen casos eutiroideos (enfermedad oftálmica de Graves). Representa la manifestación extratiroidea más frecuente en la enfermedad de Graves (10-25\%) y suele afectar en mayor proporción a mujeres entre los 20-45 años.

La historia natural de la OG pasa por una fase activa o inflamatoria de rápida progresión de la enfermedad, seguida de una regresión parcial y fase inactiva en la que las manifestaciones residuales apenas muestran cambio sustancial y son ya subsidiarios de tratamiento quirúrgico, muscular y palpebral fundamentalmente.

El manejo terapéutico se establece en función del grado de actividad y la severidad (tabla I) siendo los corticoides a altas dosis y/o la radioterapia orbitaria las opciones más efectivas para los casos severos en fase activa (1).

Recientemente se ha demostrado mediante escintografía con octreótido (Octreoscan, Mallinckrodt, St. Louis, MO, EEUU) la existencia de receptores para la somatostatina en el tejido orbitario durante la fase activa de la enfermedad lo que convertiría a estos pacientes en subsidiarios al tratamiento con los análogos de la somatostatina (2).

\section{CASO CLÍNICO}

Varón de 42 años remitido a nuestro hospital por episodios recurrentes de conjuntivitis y epiescleritis que no mejoraban con el tratamiento convencional.

Tabla I. Manejo terapéutico de la oftalmopatía tiroidea según grado de actividad y severidad

\begin{tabular}{|c|c|c|}
\hline $\begin{array}{l}\text { Afectación } \\
\text { ocular }\end{array}$ & $\begin{array}{l}\text { Grado de } \\
\text { actividad }\end{array}$ & Tratamiento \\
\hline No-severo & Activo & Medidas de soporte \\
\hline No-severo & Inactivo & Medidas de soporte \\
\hline Severo & Activo & $\begin{array}{l}\text { Consolidados: } \uparrow \text { dosis glucocort, } \\
\text { Rt y Qx } \\
\text { En estudio: análogos } \\
\text { somatostatina, Ig iv } \\
\text { Sin consolidar: ciclosporina, } \\
\text { plasmaféresis }\end{array}$ \\
\hline Severo & Inactivo & $\begin{array}{l}\text { Descompresión orbitaria } \\
\text { Cirugía del estrabismo } \\
\text { Cirugía palpebral }\end{array}$ \\
\hline
\end{tabular}

No refería antecedentes personales ni oftalmológicos de interés, tan sólo hábito tabáquico de aproximadamente una cajetilla al día.

A la exploración oftalmológica la agudeza visual (AV) corregida era de la unidad en ambos ojos; los hallazgos biomicroscópicos comprendían inyección y quemosis conjuntival $+/+++$, edema palpebral superior y un queratitis punteada superficial inferior. No presentaba retracción palpebral ni exoftalmos y la presión intraocular (PIO) era de 13/11 mmHg. Clasificación según el índice NONSPECS de 2-b, 5-a.

La analítica básica (bioquímica y hemograma) era normal, las hormonas tiroideas $\left(\mathrm{T}_{3}, \mathrm{~T}_{4}, \mathrm{TSH}\right)$ estaban elevadas. Se remitió el paciente al endocrinólogo con el diagnóstico de OG leve-moderada en fase activa quien instauró tratamiento antitiroideo junto al tratamiento tópico ocular oftalmológico.

En revisiones posteriores se apreció la progresión de la oftalmopatía hacia un estadio moderado-severo (fig. 1) con empeoramiento de los signos biomicroscópicos, desarrollo de retracción palpebral superior de $3 \mathrm{~mm}$ en ambos ojos e inferior de $2 \mathrm{~mm}$ en ojo derecho (OD) y $1 \mathrm{~mm}$ en el izquierdo (OI), exoftalmometría de Hertel de $25 \mathrm{~mm}$ en OD y 24 $\mathrm{mm}$ en el OI y aumento de la PIO $(24 / 22 \mathrm{mmHg})$. Se realizó un octreoscan, que consiste en una inyección de $6 \mathrm{mg}$ de $\mathrm{In}^{111}$-octreótido intravenoso y realización de imágenes planares con estudio mediante tomografía por emisión de fotones a las cuatro y veinticuatro horas. Estas imágenes revelaron la presencia de actividad a nivel orbitario utilizando un método cualitativo de contraste comparando la captación respecto a la de fondo (tejido óseo occipital) (fig. 2), por lo que, se inició tratamiento con lanreó-

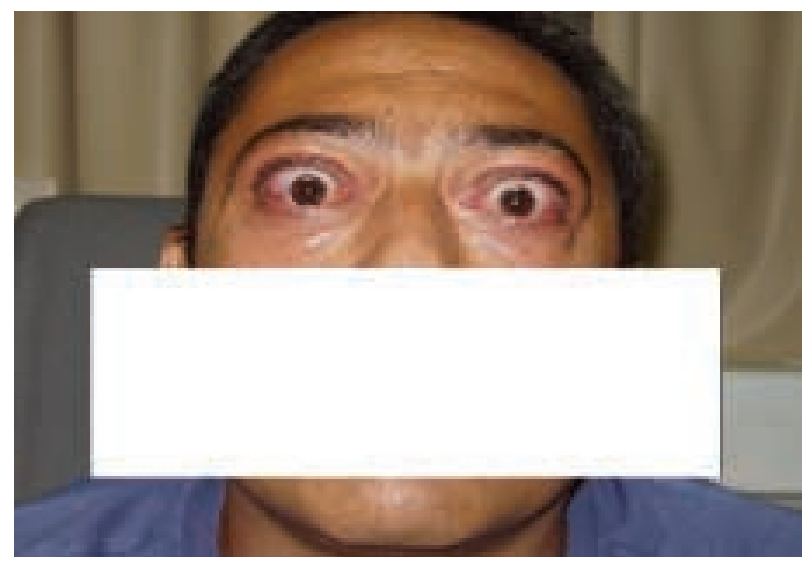

Fig. 1: Aspecto del paciente antes de tratamiento. 
tido $90 \mathrm{mg}$ cada 3 semanas durante 2 meses, seguido de $60 \mathrm{mg}$ intramuscular cada 15 días durante 2 meses más.

Tras el tratamiento, se repitió la prueba comprobándose un descenso en la captación orbitaria (fig. 3). La AV corregida era de 1 en el OD y 0,9 en el OI, persistiendo una leve epiteliopatía corneal inferior. La PIO era de 17/14 mm $\mathrm{Hg}$ con tratamiento tópico hipotensor en OD y trabeculectomía en OI (al mes de iniciar tratamiento) debido a hipertensión mantenida $(\approx 36 \mathrm{mmHg})$ sin respuesta al tratamiento médico. La exoftalmometría de $22 \mathrm{~mm}$ AO y la retracción palpebral superior de $2 \mathrm{~mm}$ e inferior de $1 \mathrm{~mm}$ AO a la espera de corrección quirúrgica.

\section{DISCUSIÓN}

La evolución general de nuestro paciente fue buena llegando a la fase inactiva sin secuelas importantes. La agudeza visual se mantuvo entre 1-0,9 con fluctuaciones a considerar sólo tras la realización de una trabeculectomía en el ojo izquierdo por tensiones intraoculares no controlables con tratamiento tópico hipotensor. Los signos y, sobre todo, los síntomas inflamatorios, mostraron una respuesta adecuada al tratamiento. Los valores exoftalmométricos se redujeron entre $2-3 \mathrm{~mm}$ mientras que la retracción palpebral apenas mostró cambio $(1 \mathrm{~mm})$, al igual que la restricción muscular.

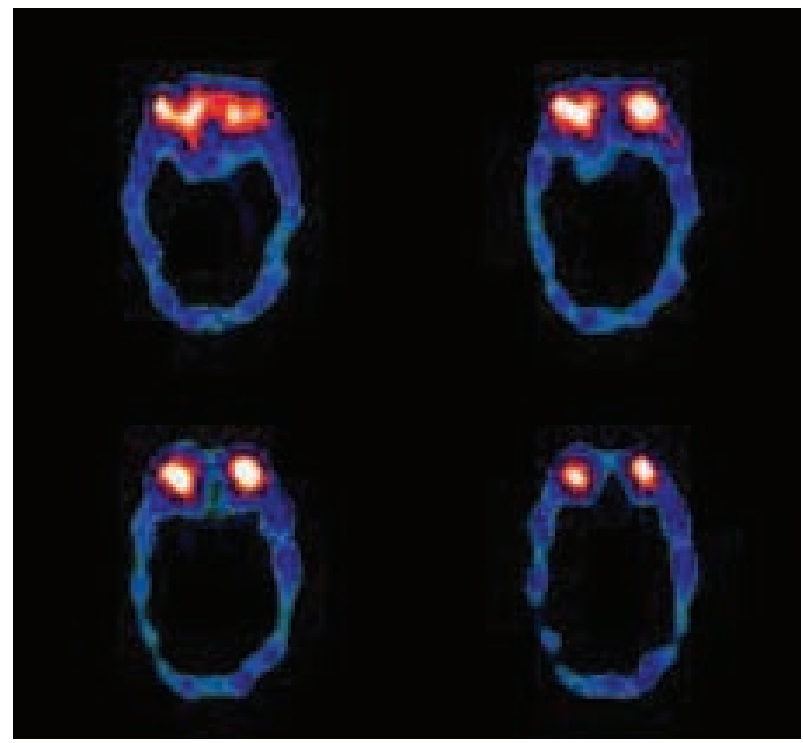

Fig. 2: Imagen de octreoscan antes del tratamiento que muestra aumento de la captación a nivel orbitario.
Nuestros resultados concuerdan con los observados en estudios previos y son, a nuestro parecer, prometedores pues muestran el posible efecto que este tipo de tratamiento podría tener sobre parámetros como la proptosis que no se ven influenciados por otros tratamientos en uso.

Además, los efectos secundarios de los análogos de la somatostatina (malestar local en zona de inyección, alteraciones leves de la glucemia y alteraciones digestivas tipo nauseas, diarrea y menos frecuentemente cálculos biliares y gastritis) son de menor relevancia que los relacionados con los corticoides y la radioterapia de uso tan generalizado en el manejo de este tipo de pacientes.

Teniendo en cuenta que los análogos de la somatostatina inhiben la proliferación de linfocitos y fibroblastos (células protagonistas en la enfermedad de Graves), así como, la producción de citoquinas y la acción del IGF-I, con su uso se consigue actuar sobre los factores desencadenantes y perpetuantes del proceso frenándolo y no sólo a nivel de los efectos del mismo.

En este caso se empleó como primera y única opción terapeútica el lanreótido a sugerencia de la casa comercial ya que el paciente no se encontraba en un estadio crítico. Sin embargo, todavía se precisan más estudios para comprobar que el efecto terapéutico observado es en realidad debido al tratamiento y no resultado de la evolución natural del proceso hacia la remisión (3). Así como, para pro-

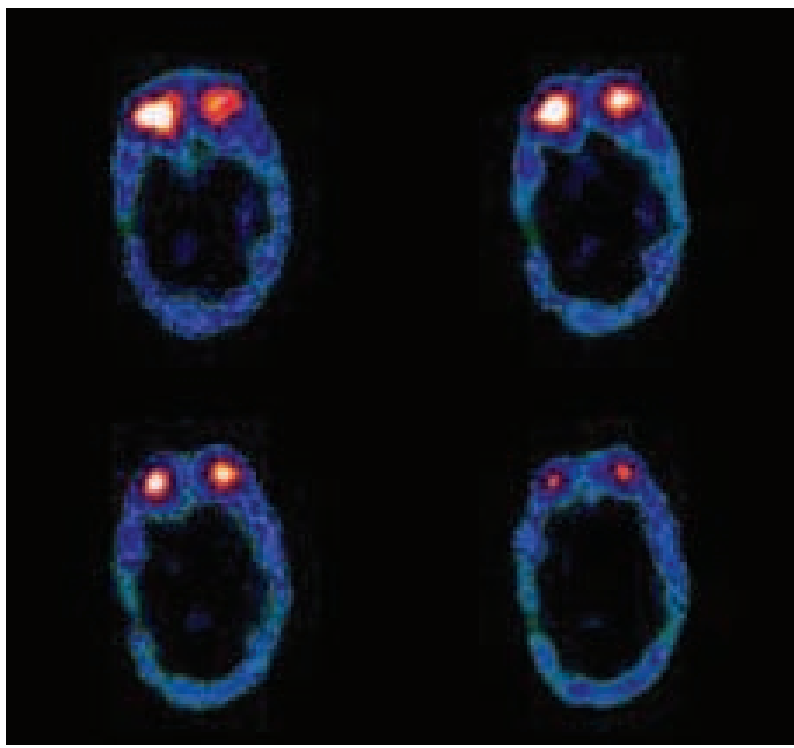

Fig. 3: Imagen de octreoscan tras tratamiento con normalización de la captación. 
bar la combinación de estos con otros tratamientos tales como los corticoides y los nuevos análogos que han ido apareciendo (SOM230) con mayor afinidad por los receptores de la somatostatina presentes en el tejido orbitario (4).

Como inconvenientes a esta opción terapéutica encontramos la necesidad de contar con el equipo del octreoscan (5) o acceso al mismo.

\section{BIBLIOGRAFÍA}

1. Perros $P$, Kendall-Taylor P. Medical treatment for thyroid-associated ophthalmopathy. Thyroid 2002; 12: 241 244.
2. Pasquali D, Vassallo P, Esposito D, Bonavolonta $G$, Bellastella A, Sinisi AA. Somatostatin receptor gene expression and inhibitory effects of octreotide on primary cultures of orbital fibroblasts from Graves' ophthalmopathy. J Mol Endocrinol 2000; 25: 63-71.

3. Perros P, Crombie AL, Kendall-Taylor P. Natural history of thyroid associated ophthalmopathy. Clin Endocrinol (Oxf) 1995; 42: 45-50.

4. Bruns $C$, Lewis I, Briner U, Meno-Tetang G, Weckbecker G. SOM230: a novel somatostatin peptidomimetic with broad somatotropin release inhibiting factor (SRIF) receptor binding and a unique antisecretory profile. Eur J Endocrinol 2002; 146: 707-716.

5. Gerding MN, van der Zant FM, van Royen EA, Koornneef L, Krenning EP, Wiersinga WM, et al. Octeotride-scintigraphy is a disease-activity parameter in Graves' ophtalmopathy. Clin Endocrinol (Oxf) 1999; 50: 373-379. 